\title{
Método para determinação de volume específico como padrão de qualidade do polvilho azedo e sucedâneos
}

\author{
Method for the determination of specific volume as a quality standard for \\ fermented cassava starch and substitutes
}

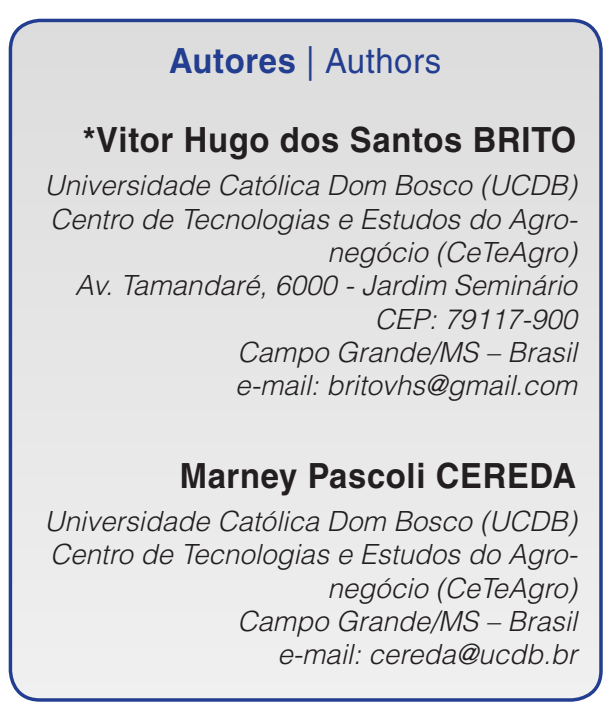

*Autor Correspondente / Corresponding Author

Recebido: Fev. 05, 2014

Aprovado: Mar. 31, 2015

\section{Resumo}

Objetivou-se estabelecer um método para a determinação da expansão como critério de qualidade do polvilho azedo e sucedâneos. Três tipos de amidos de mandioca foram avaliados: Polvilho Azedo (padrão), Expandex $x^{\circledR}$ e Amido Nativo. As amostras foram condicionadas diretamente em moldes de silicone e metal revestido com politetrafluoretileno e forneadas sob condições controladas de temperatura $200{ }^{\circ} \mathrm{C}$ ou $250{ }^{\circ} \mathrm{C}$ e tempo 20 ou 25 minutos. O método proposto foi avaliado pela repetitividade do volume específico (relação volume:massa) e os resultados foram comparados com os obtidos por método tradicional com manuseio dos ingredientes com água fervente e moldeamento manual em bolas, posteriormente forneadas em assadeira de alumínio untada, assadas nas mesmas condições. A seleção do melhor método levou em conta os maiores valores para volume específico $\left(\mathrm{cm}^{3} \mathrm{~g}^{-1}\right)$ e menores variações entre as repetições. Para a fôrma de silicone, os melhores resultados foram obtidos nas condições de $200^{\circ} \mathrm{C}$ e $25 \mathrm{~min}\left(8,89 \mathrm{~cm}^{3} \mathrm{~g}^{-1} \mathrm{com} 1,46 \%\right.$ de variabilidade), que proporcionou massas suficientemente resistentes ao manuseio para permitir as medidas. Para moldes de politetrafluoroetileno as melhores condições foram temperatura de $200{ }^{\circ} \mathrm{C}$ durante 0 tempo de 20 minutos $\left(8,16 \mathrm{~cm}^{3} \mathrm{~g}^{-1} \mathrm{com}\right.$ $7,59 \%$ de variabilidade). A amostra de Expandex ${ }^{\circledR}$ apresentou a mesma resposta que o polvilho azedo às variáveis de temperatura de forno e tempo de assamento, porém com valores maiores. A presença residual de grânulos intactos mostrou que a gelatinização do amido não foi completa nas condições de forneamento. O método proposto apresentou facilidade na manipulação e o tempo necessário foi apenas aquele necessário para a elaboração da pasta com água e o forneamento.

Palavras-chave: Padronização; Qualidade de polvilho azedo; Amido modificado; Expansão.

\section{Summary}

The objective was to establish a method for the determination of the expansion of cassava starch and substitutes as a quality standard. Three types of cassava starch were evaluated: Fermented Cassava Starch, Expandex ${ }^{\circledR}$ and Native Starch. The samples were put directly into silicone or metal polytetrafluoroethylene moulds and baked under controlled conditions of temperature $\left(200\right.$ or $250^{\circ} \mathrm{C}$ ) and time ( 20 or 25 minutes). The proposed method was evaluated by the repeatability of the specific volume (volume ratio:mass) and the results compared with those obtained by the traditional method, in which the ingredients were handled in boiling water, moulded into balls by hand, and subsequently baked in greased aluminium baking pans under the same conditions. The selection of the best method took into account the highest values for specific volume $\left(\mathrm{cm}^{3} \mathrm{~g}^{-1}\right)$ and the least variations between repetitions. For the silicon mould, the best results were obtained under the conditions of $200^{\circ} \mathrm{C}$ and $25 \mathrm{~min}(8.89$ $\mathrm{cm}^{3} \mathrm{~g}^{-1}$ with $1.46 \%$ variability), which provided pastas sufficiently resistant to handling to allow for the taking of measurements. For the polytetrafluoroethylene moulds, the best conditions were $200{ }^{\circ} \mathrm{C}$ for 20 minutes $\left(8.16 \mathrm{~cm}^{3} \mathrm{~g}^{-1}\right.$ with $7.59 \%$ variability). The sample Expandex ${ }^{\circledR}$ showed the same response as cassava starch to the variables of oven temperature and baking time, but showed higher values. The presence of residual intact granules showed that gelatinization of the starch was not completed under the baking conditions used. The proposed method showed ease of handling and the time required was just that necessary to knead the dough with water and bake it.

Key words: Standardization; Fermented cassava starch quality; Modified starch; Expansion. 


\section{Introdução}

Os amidos modificados disponíveis no mercado atendem às necessidades de aplicação industrial, necessidades essas que têm as mais expressivas variações em processamento de alimentos.

Em geral, os amidos nativos não apresentam a propriedade de expansão e, no preparo de produtos panificáveis, o aumento de volume é obtido pelo uso de fermento químico, biológico ou por extrusão (PLATA-OVIEDO e CAMARGO, 1998; LEONEL et al., 2004). No caso do uso de extrusor, o aumento de volume depende apenas de processo físico, caracterizado pela brusca variação de pressão (CAMARGO et al., 2008).

Na América do Sul, são elaborados produtos panificáveis tradicionais, nos quais é possível conseguir expansão da massa no forno, sem uso de fermento ou extrusão. Em comum, todos esses produtos expandidos usam polvilho azedo, mas apresentam nomes típicos em cada país, tais como "cuñape", na Bolívia, "pandebono", na Colômbia ou "chipa", no Paraguai (MILDE et al., 2009; LOPEZTENORIO et al., 2012) e no estado do Mato Grosso do Sul. O produto brasileiro equivalente é o conhecido pão de queijo.

No polvilho azedo ou amidos com propriedade de expansão (sucedâneos), o aumento do volume específico das massas é atribuído à pressão interna de gases e vapor de água durante o forneamento, atuantes no desenvolvimento de uma rede polimérica por meio da formação de ligações de pontes de hidrogênio entre as moléculas de água e os grupos carboxilas e hidroxilas do amido (MARCON et al., 2009).

O polvilho azedo é produzido em grau mais ou menos industrializado em todo o país (WESTBY e CEREDA, 1994) e, mais recentemente, teve seu volume de produção aumentado pela popularização do consumo de pão de queijo que, de um nicho tradicional na culinária mineira, passou a fast food, consumido em larga escala, e exigindo padronização da qualidade do produto (ANJOS et al., 2014).

Embora reconhecido como produto alimentar, a Legislação Brasileira de Normas Técnicas Especiais Relativas a Alimentos e Bebidas (BRASIL, 1978) não legitima a propriedade de expansão como critério de qualidade para esse tipo de amido modificado, e a ANVISA (BRASIL, 2005) não especifica uma metodologia preconizada para sua análise.

O aumento de consumo do pão de queijo passou a exigir melhor qualidade, o que por sua vez exigiu maior padronização do polvilho azedo, incluindo o conteúdo microbiano, a formação de estrutura alveolar adequada e a crocância característica de snacks extrusados (BERTOLINI et al., 2001; LEONEL et al., 2004), que dependem da expansão ao forno (DEMIATE e KOTOVICZ, 2011).
Uma vez que a ANVISA (BRASIL, 2005) não estabelece uma metodologia padrão, a questão da avaliação da qualidade de expansão fica a critério dos produtores e comerciantes, mas é ainda mais crítica quando necessária em pesquisas.

Os primeiros métodos de avaliação da propriedade de expansão do polvilho azedo como critério de qualidade basearam-se no processo caseiro de utilização em pão de queijo ou biscoito de polvilho, com formulação rica, que incluía matérias-primas de alta variabilidade como queijo, leite e ovos, na mesma proporção usada em padarias. Além disso, para conseguir consistência adequada era realizado o escaldamento, processo utilizado nas residências e padarias, que consistia em despejar sobre o polvilho azedo um volume estabelecido de uma mistura fervente de leite, água e óleo ou gordura vegetal hidrogenada. Além dos ingredientes, o escaldamento era outro fator de erro, em razão da dificuldade em manter a temperatura adequada pelo tempo necessário (CEREDA, 1983; MAEDA e CEREDA, 2001; APLEVICZ e DEMIATE, 2007).

Cada vez mais a qualidade estável de polvilho azedo é exigência para sua comercialização. A pesquisa para o desenvolvimento de novos produtos também exige uma metodologia mais precisa e de maior reprodutibilidade, a partir de menor quantidade de amostra, razão pela qual, no presente trabalho, objetivou-se estabelecer um método para a determinação do volume específico de massas assadas de polvilho azedo e amidos com propriedade de expansão, onde apenas amido e água sejam usados na elaboração das massas.

\section{Material e métodos}

\subsection{Amostras}

Três amostras de amido de mandioca comerciais foram selecionadas: Amido Nativo marca Paranaense ${ }^{\circledR}$ (12\% umidade), Polvilho Azedo marca Yoki $^{\circledR}(12 \%$ umidade) e amido modificado Expandex ${ }^{\circledR}(13 \%$ umidade), desenvolvido pela Corn Products ${ }^{\circledR}$ Brasil, para substituir o polvilho azedo por apresentar propriedade de expansão.

\subsection{Planejamento experimental}

O arranjo experimental foi constituído por 2 temperaturas (200 ou $250{ }^{\circ} \mathrm{C}$ ), 3 materiais (método tradicional e forneamento em assadeira de alumínio untada, moldes de silicone e molde de metal revestido com politetrafluoretileno), e 2 tempos de forneamento (20 ou 25 minutos). As variáveis foram avaliadas para os 3 tipos de amidos comerciais de mandioca, com 10 repetições para cada, totalizando 120 mensurações (n) para cada amostra. 


\subsection{Metodologia tradicional com escaldamento}

O método seguiu rigorosamente a literatura (CEREDA, 1983). As formulações das massas foram baseadas no cálculo do peso da amostra de amido $(100 \%)$ e os demais ingredientes calculados como porcentagem sobre este ingrediente. A quantidade de gordura vegetal hidrogenada foi de $25 \%$, sal, $4 \%$ e água ao redor de 80\%, variável em função da amostra. O escaldamento constou da adição de água potável (pH 6,8) fervente $\left(90^{\circ} \mathrm{C}\right.$ no local do experimento) vertida direta e gradualmente sobre o amido. O escaldamento foi interrompido quando a massa adquiriu a consistência necessária para ser moldada nas mãos.

A massa foi então dividida em porções com cerca de $10 \mathrm{~g}$, que foram arredondadas à mão, identificadas com tinta à prova de água e distribuídas aleatoriamente em assadeira de alumínio previamente untada com gordura vegetal hidrogenada. Posteriormente, as massas foram condicionadas conforme os itens 2.5 e 2.6 .

\subsection{Proposta de método simplificado sem escaldamento}

As mesmas amostras de amido foram avaliadas pela metodologia proposta, que dispensa o escaldamento. Nesse caso, as massas foram confeccionadas diretamente nos moldes com amido e água na proporção 1:1 (massa:volume), sem a necessidade de untá-las com gordura. A mistura em quantidades iguais de água potável $\left(5 \mathrm{~cm}^{3}\right) \mathrm{com} \mathrm{pH} 6,8$, em temperatura ambiente, e $5 \mathrm{~g}$ de amido (MS) foi homogeneizada com o auxílio de uma espátula.

Para eliminar a necessidade de uso de assadeira untada, foram avaliados moldes individuais em silicone (Tupperware ${ }^{\circledR}$ ) com capacidade de $65 \mathrm{~cm}^{3}$ e assadeira metálica revestida de politetrafluoretileno (Meister ${ }^{\circledR}$ ) com 6 cavidades de $75 \mathrm{~cm}^{3}$. Posteriormente, as massas foram condicionadas conforme os itens 2.5 e 2.6.

\subsection{Forneamento}

Os três amidos comerciais foram avaliados, para a verificação do poder de expansão, em assadeira de alumínio (método tradicional) e em moldes de silicone e de metal revestido com politetrafluoretileno. As amostras foram condicionadas em forno elétrico termostático, marca Diplomata ${ }^{\circledR}$, pré-aquecido. As variáveis foram duas temperaturas (200 ou $250{ }^{\circ} \mathrm{C}$ ) e dois tempos de forneamento (20 ou 25 minutos) para as duas metodologias (com e sem escaldamento). Depois de resfriadas à temperatura ambiente (em dessecador), durante 5 minutos, as massas assadas foram avaliadas quanto ao volume específico e às características da massa assada, fatores selecionados como variáveis dependentes.

\subsection{Determinação do volume específico}

O volume específico foi estabelecido pelo quociente entre o volume $\left(\mathrm{cm}^{3}\right)$ e a massa $(\mathrm{g})$ de cada amostra forneada, com resultados expressos em $\mathrm{cm}^{3} \mathrm{~g}^{-1}$. A massa foi obtida em balança analítica (Bel Engineering ${ }^{\circledR}$ MG 164A) e o volume pelo deslocamento de sementes de painço, aferido em proveta $50 \mathrm{~cm}^{3}$ (Equação 1).

$V E=\frac{V}{m}$

Em que: VE = volume específico $\left(\mathrm{cm}^{3} \mathrm{~g}^{-1}\right) ; \mathrm{V}=$ volume $\left(\mathrm{cm}^{3}\right) ; \mathrm{m}=$ massa $(\mathrm{g})$.

\subsection{Análise estatística}

Com os resultados foram estabelecidos a Média, Desvio Padrão $(\sigma)$. Para a avaliação da repetibilidade das análises foi estabelecido a variabilidade por meio do Coeficiente de Variação (CV\%). As médias foram avaliadas por meio de análise de variância (ANOVA) ao nível de $5 \%$ de significância ( $p>0,05)$.

\subsection{Microscopia (massas expandidas)}

Para avaliar a permanência de amido não gelatinizado (grânulos) após forneamento, foram obtidas imagens com microscópio digital ProscopeHr ${ }^{\mathrm{TM}}$ (aumento de 200 vezes). Com auxílio de uma lâmina, foi retirado material de pontos distintos das massas forneadas. Esse material foi suspenso em água e corado com lugol.

\section{Resultados e discussão}

A metodologia de avaliação da qualidade do polvilho azedo pelo volume específico é adotada no Brasil e em países que produzem algum tipo de amido com propriedade de expansão, especialmente na Colômbia (WESTBY e CEREDA, 1994).

$\mathrm{Na}$ Tabela 1 são apresentados os resultados de volume específico. É notável a variabilidade dos resultados em função do tipo de procedimento adotado (escaldamento, molde silicone ou molde metálico revestido com politetrafluoretileno) e das variáveis (temperatura e tempo). A amostra de polvilho azedo comercial, quando escaldada, proporcionou produtos com baixo volume específico nas condições de forneamento a $200{ }^{\circ} \mathrm{C}$, efeito relacionado ao desenvolvimento de crosta rígida e formato disforme. Além disso, a variabilidade dos resultados entre as repetições de cada procedimento foi intermediária quando comparada com o uso de molde de silicone e molde metálico revestido com politetrafluoretileno, apresentando variação de 3,37 a 7,59\% (Tabela 1).

O uso combinado de escaldamento e de bandeja de alumínio untada é o método mais conhecido, razão pela qual é o principal citado na literatura, entretanto, problemas são relacionados a essa metodologia devido à 
Método para determinação de volume específico como padrão de qualidade do polvilho azedo e sucedâneos

BRITO, V. H. S. e CEREDA, M. P.

etapa de escaldamento, que é de difícil reprodutibilidade, uma vez que a variabilidade da composição da mistura de água fervente, gordura vegetal hidrogenada e leite, dificulta a dosagem e a manutenção da temperatura adequada, além dos riscos de acidentes com os operadores envolvidos.

Diferenças mais visíveis são observadas quando a mesma amostra de polvilho azedo foi avaliada por meio da metodologia proposta, sem escaldamento e com a massa elaborada diretamente nos moldes. Quando foi usado molde de metal revestido com politetrafluoretileno e forno a $250{ }^{\circ} \mathrm{C}$ durante 20 ou 25 minutos, os valores de expansão foram maiores que os obtidos no método tradicional (Tabela 1). Entretanto, com o uso desse tipo de material, as massas expandidas queimaram, aumentando a fragilidade e a dificuldade de manuseio, inviabilizando o uso nessas condições (Tabela 1).

Um comparativo visual entre a influência das condições de forneamento e a capacidade expansiva das amostras pelos três procedimentos pode ser observado na Figura 1.

Quando o molde de metal revestido com politetrafluoretileno foi substituído pelo de silicone, os resultados de volume específico melhoraram do ponto de vista de facilidade de manuseio, com exceção para o forneamento a $250{ }^{\circ} \mathrm{C}$ durante 25 minutos, onde houve o rompimento da estrutura de 3 das 10 mensurações (Figura 1, imagem 2D), permitindo o emprego de apenas 7 unidades na avaliação.

O uso de molde de silicone na temperatura de $200{ }^{\circ} \mathrm{C}$, independente do tempo de forneamento, facilitou a mensuração do volume específico que foi de 5,37 e $8,89 \mathrm{~cm}^{3} \mathrm{~g}^{-1}$, além de propiciar baixa variabilidade entre as repetições, 0,37 a $1,46 \%$ respectivamente (Figura 1 , imagens $2 \mathrm{~A}$ e $2 \mathrm{~B}$ ).

O amido modificado comercializado como Expandex ${ }^{\circledR}$ é um sucedâneo de polvilho azedo, desenvolvido devido à falta de padronização do produto tradicional (MAEDA e CEREDA, 2001; APLEVICZ e DEMIATE, 2007). Entretanto, seu alto custo e o forte odor de ácido acético dificultaram sua aceitação, embora sua expansão se mantenha estável por longo período. Exatamente por se tratar de produto com alta e estável expansão, foi considerado importante avaliar esse amido modificado pela metodologia sem uso de escaldamento. Os resultados obtidos estão dispostos na Tabela 2 e comprovaram que os efeitos das variáveis selecionadas sobre o volume específico das massas foram semelhantes aos efeitos obtidos para a amostra de polvilho azedo.

O molde de metal com politetrafluoretileno proporcionou maiores valores de volume específico para a amostra de Expandex ${ }^{\circledR}$, variando de 14,29 a $18,14 \mathrm{~cm}^{3}$

Tabela 1. Valores de volume específico de massas assadas de Polvilho Azedo, como resultados das variáveis: temperatura (200 ou $250^{\circ} \mathrm{C}$ ), tempo (20 ou 25 minutos) e material (método tradicional, molde de silicone e de metal com politetrafluoretileno) (média de 10 replicatas).

\begin{tabular}{|c|c|c|c|c|c|c|}
\hline \multirow{3}{*}{$\begin{array}{l}\text { Polvilho Azedo } \\
\text { Condições de } \\
\text { Forneamento }\end{array}$} & \multicolumn{5}{|c|}{ Volume Específico $\left(\mathrm{cm}^{3} \mathrm{~g}^{-1}\right)$} & \multirow[b]{3}{*}{ CV\% } \\
\hline & \multicolumn{2}{|c|}{ Método } & \multicolumn{3}{|c|}{ Material do molde } & \\
\hline & Tradicional* & CV\% & Silicone & CV\% & $\begin{array}{l}\text { Politetra- } \\
\text { fluoretileno }\end{array}$ & \\
\hline 20 minutos a $200{ }^{\circ} \mathrm{C}$ & $4,15 \mathrm{dc}$ & 3,37 & $5,37 \mathrm{~dB}$ & 0,37 & $8,16^{\mathrm{cA}}$ & 7,59 \\
\hline 25 minutos a $200{ }^{\circ} \mathrm{C}$ & $5,27 \mathrm{cc}$ & 7,59 & 8,89 aA & 1,46 & $7,70 \mathrm{cB}$ & 4,93 \\
\hline 20 minutos a $250{ }^{\circ} \mathrm{C}$ & 6,56 bB & 5,79 & $6,76 \mathrm{cB}$ & 1,03 & 13,41 aA & 4,10 \\
\hline 25 minutos a $250^{\circ} \mathrm{C}$ & $8,27 \mathrm{aB}$ & 4,95 & $7,816 \mathrm{bB}$ & 0,76 & $12,31 \mathrm{bA}$ & 4,87 \\
\hline
\end{tabular}

*Não apresentam diferença significativa letras iguais minúsculas na coluna para tempo e temperatura de forneamento e letras maiúsculas iguais na linha, para o tipo de material empregado $(p>0,05)$ ou método tradicional com escaldamento (CEREDA, 1983).

Tabela 2. Valores de volume específico de massas assadas, elaboradas com amido modificado Expandex ${ }^{\circledR}$, como resultados das variáveis: temperatura $\left(200\right.$ ou $250{ }^{\circ} \mathrm{C}$ ), tempo (20 ou 25 minutos) e material (método tradicional, molde de silicone e de metal revestido com politetrafluoretileno) (média de 10 replicatas).

\begin{tabular}{|c|c|c|c|c|c|c|}
\hline \multirow{3}{*}{$\begin{array}{c}\text { Expandex }^{\circledR} \\
\text { Condições de } \\
\text { Forneamento }\end{array}$} & \multicolumn{5}{|c|}{ Volume Específico $\left(\mathrm{cm}^{3} \mathrm{~g}^{-1}\right)$} & \multirow[b]{3}{*}{ CV\% } \\
\hline & \multicolumn{2}{|c|}{ Método } & \multicolumn{3}{|c|}{ Material do molde } & \\
\hline & Tradicional* $^{*}$ & CV\% & Silicone & $\mathrm{CV} \%$ & $\begin{array}{c}\text { Politetra- } \\
\text { fluoretileno }\end{array}$ & \\
\hline 20 minutos a $200^{\circ} \mathrm{C}$ & $5,25^{c c}$ & 6,85 & $10,86^{c B}$ & 1,47 & $14,29 \mathrm{cA}$ & 5,66 \\
\hline 25 minutos a $200{ }^{\circ} \mathrm{C}$ & $5,21^{c c}$ & 3,83 & $12,31 \mathrm{bB}$ & 1,29 & 16,07 bA & 5,04 \\
\hline 20 minutos a $250^{\circ} \mathrm{C}$ & $8,42^{b c}$ & 4,63 & $10,25^{c B}$ & 1,75 & $17,82^{\text {aA }}$ & 6,00 \\
\hline 25 minutos a $250{ }^{\circ} \mathrm{C}$ & 11,19 ac & 13,76 & 13,57 aв & 2,65 & $18,14^{\text {aA }}$ & 4,13 \\
\hline
\end{tabular}

*Não apresentam diferença significativa letras iguais minúsculas na coluna para tempo e temperatura de forneamento e letras maiúsculas iguais na linha, para o tipo de material empregado $(p>0,05)$ ou método tradicional com escaldamento (CEREDA, 1983). 


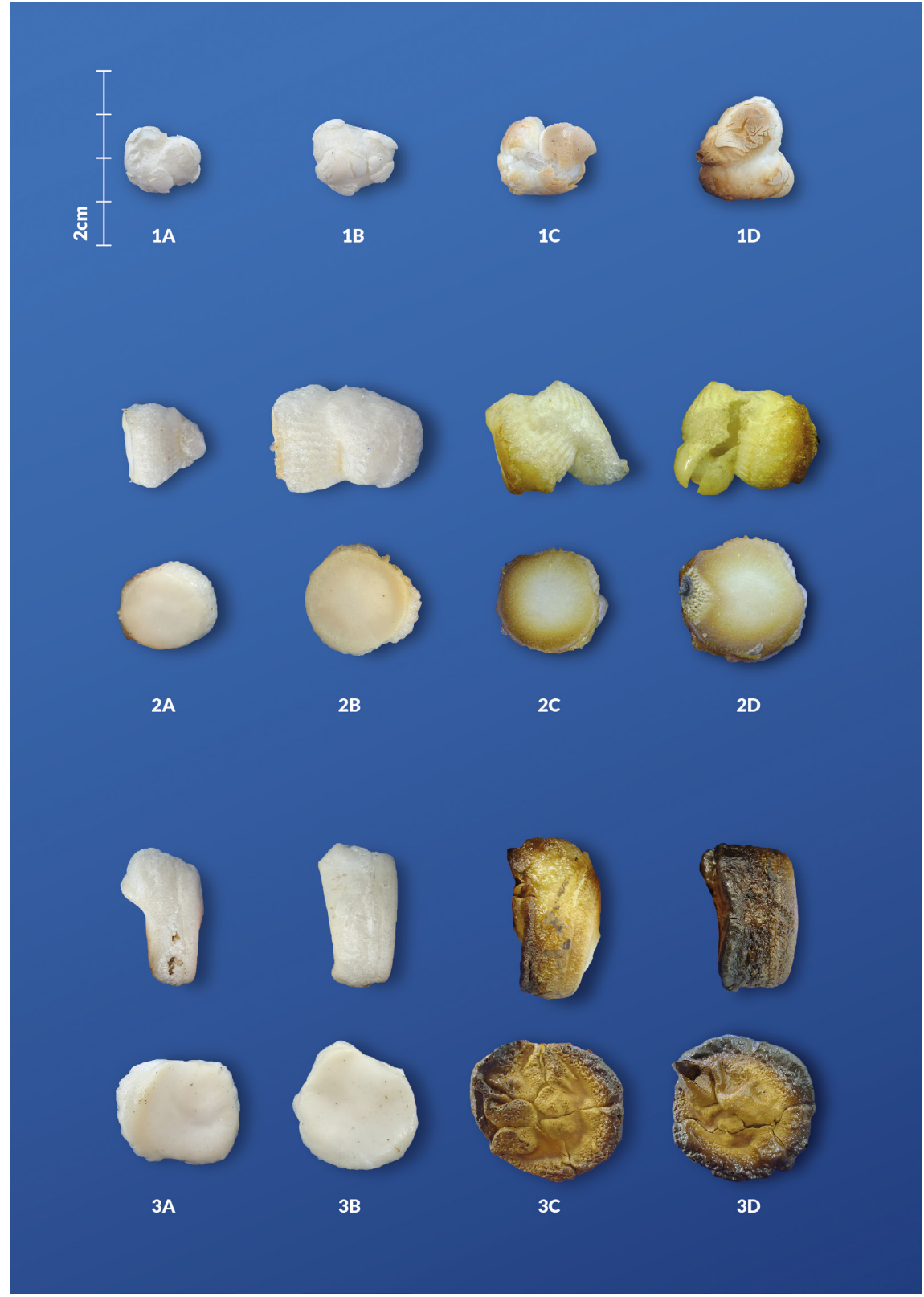

Figura 1. Aspecto das massas de Polvilho Azedo: (1) método tradicional de escaldamento e forneamento em bandeja de alumínio untada (CEREDA, 1983); (2) molde de silicone; e (3) molde de metal com politetrafluoretileno. A - Forneamento durante 20 minutos a $200{ }^{\circ} \mathrm{C}$; B - Forneamento durante 25 minutos a $200{ }^{\circ} \mathrm{C}$; C - Forneamento durante 20 minutos a $250{ }^{\circ} \mathrm{C}$; D - Forneamento durante 25 minutos a $250^{\circ} \mathrm{C}$.

$\mathrm{g}^{-1}$, com variabilidade de $10,72 \%$ entre as diferentes condições de forneamento. Com o forno regulado para $250{ }^{\circ} \mathrm{C}$, resultaram massas assadas com elevada fragilidade em ambos os tempos (20 e 25 minutos).

O método tradicional com escaldamento apresentou variação significativa de volume para o tempo de forneamento, quando o forno foi ajustado a $200^{\circ} \mathrm{C}$. Já a 250 ${ }^{\circ} \mathrm{C}$ o volume específico foi significativamente maior quando forneados por 25 minutos, bem como a variabilidade, também maior entre as repetições (3,84 e 6,86\%).

As massas apresentaram estrutura bem definida após o forneamento, resultando em repetições com valores muito próximos, possivelmente devido à maior plasticidade desse tipo de amido. Embora o molde de metal com politetrafluoretileno tenha proporcionado os maiores valores de volume específico para a amostra de Expandex ${ }^{\circledR}$, também proporcionou massas com maior fragilidade, fato observado pelo seu aspecto muito tostado, principalmente aquelas assadas a $250{ }^{\circ} \mathrm{C}$ (Figura 2, imagens 4D, 5D e 6D).

A popularização do uso de silicone no preparo de alimentos, devido à sua maior versatilidade também por não exigir ser untado com óleo ou gordura, tornou-se um diferencial para aspectos nutricionais, ainda assim 


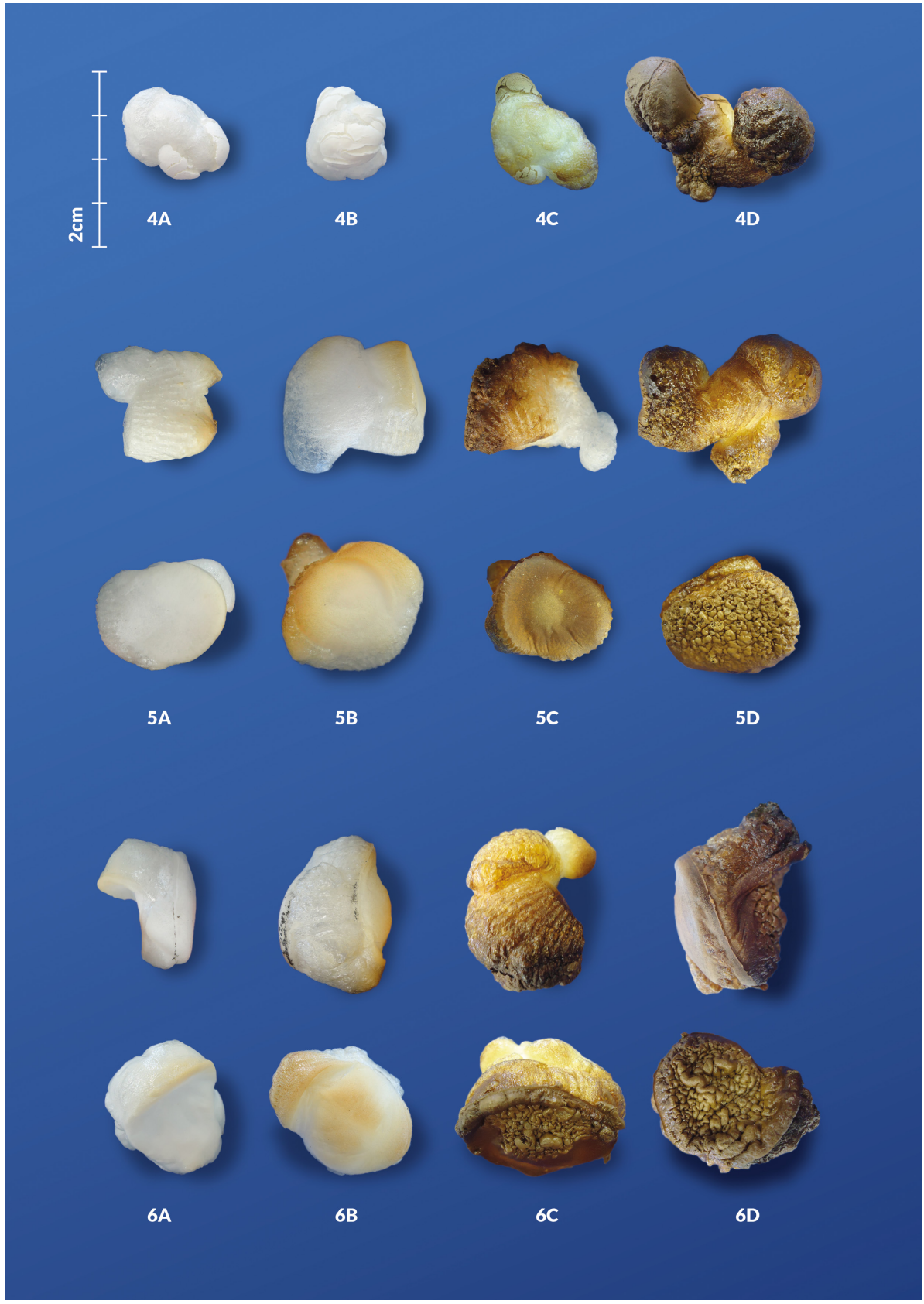

Figura 2. Aspecto das massas de Expandex ${ }^{\circledR}$ : (4) método tradicional de escaldamento e forneamento em bandeja de alumínio untada (CEREDA, 1983); (5) molde de silicone; e (6) molde de metal com politetrafluoretileno. A - Forneamento durante 20 minutos a $200{ }^{\circ} \mathrm{C}$; B - Forneamento durante 25 minutos a $200{ }^{\circ} \mathrm{C}$; C - Forneamento durante 20 minutos a $250{ }^{\circ} \mathrm{C}$; D - Forneamento durante 25 minutos a $250^{\circ} \mathrm{C}$.

não foram encontrados trabalhos de pesquisa sobre esse tipo de material em panificação. As massas assadas em moldes de silicone apresentaram valores de volume específico intermediários, porém, com menor variabilidade entre as mensurações.

Mesmo a literatura específica tendo estabelecido que o amido de mandioca nativo não apresente propriedade de expansão (FRANCO et al., 2010), nas condições em que o experimento foi realizado, foi observada a interação entre o tempo de forneamento, o material usado e a temperatura, resultando em uma variação de volume específico de 1,94 a $4,66 \mathrm{~cm}^{3} \mathrm{~g}^{-1}$ (Tabela 3 e Figura 3).

As condições de forneamento em molde de metal com politetrafluoretileno a $250{ }^{\circ} \mathrm{C}$ durante 20 ou 25 , resultaram em acentuada fragilidade das massas. Com o uso de moldes de silicone e pelo método tradicional de escaldamento, não foi detectada perda de qualidade das massas e houve diferença entre o volume específico. 


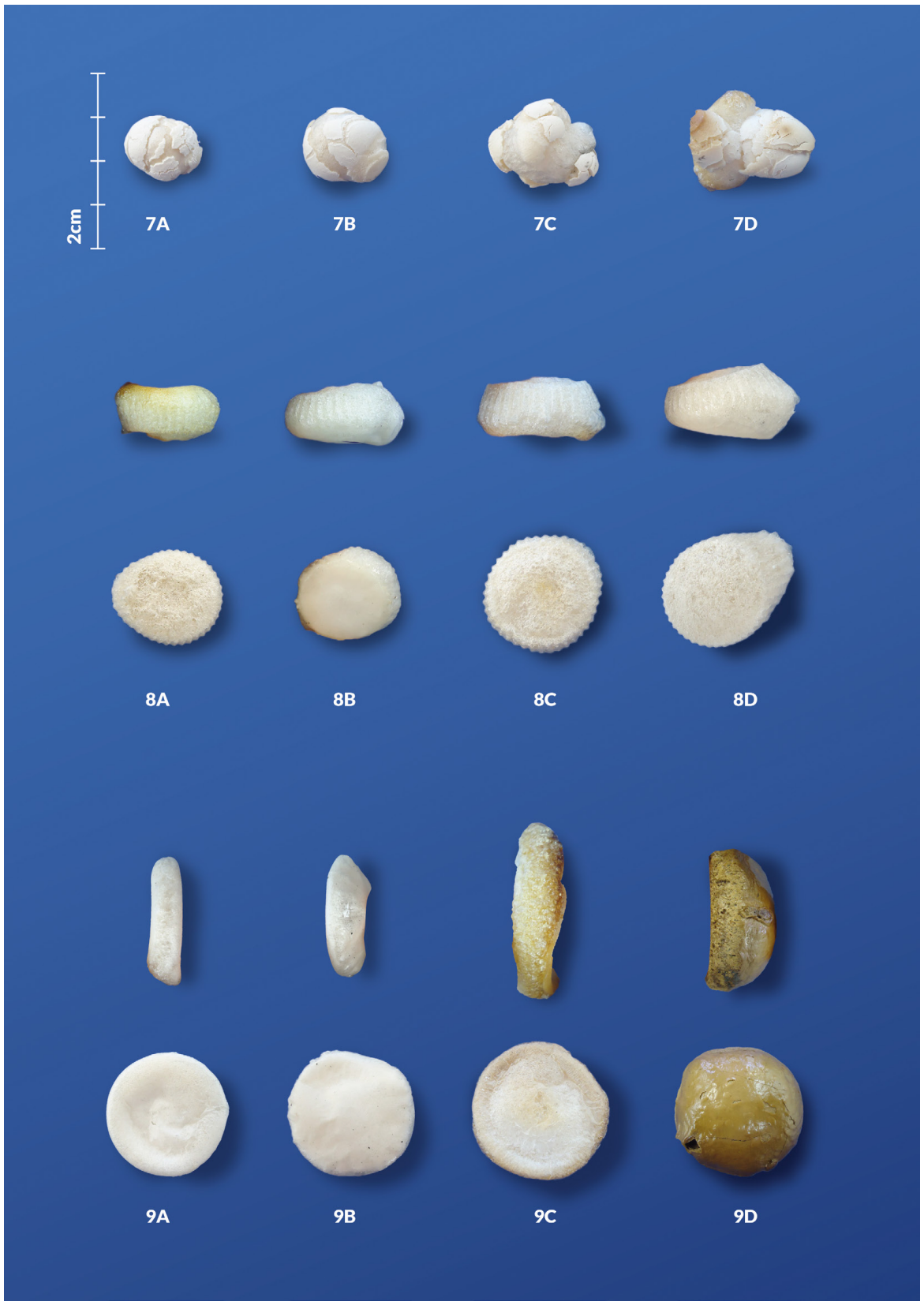

Figura 3. Aspecto das massas de Amido Nativo: (7) método tradicional de escaldamento e forneamento em bandeja de alumínio untada (CEREDA, 1983); (8) molde de silicone; e (9) molde de metal com politetrafluoretileno. A - Forneamento durante 20 minutos a $200{ }^{\circ} \mathrm{C}$; B - Forneamento durante 25 minutos a $200{ }^{\circ} \mathrm{C}$; C - Forneamento durante 20 minutos a $250{ }^{\circ} \mathrm{C}$; D - Forneamento durante 25 minutos a $250{ }^{\circ} \mathrm{C}$.

Tabela 3. Valores de volume específico de massas elaboradas com amido de mandioca nativo, como resultados das variáveis: temperatura (200 ou $250{ }^{\circ} \mathrm{C}$ ), tempo (20 ou 25 minutos) e material (método tradicional, molde de silicone e de metal com politetrafluoretileno) (média de 10 replicatas).

\begin{tabular}{|c|c|c|c|c|c|c|}
\hline \multirow{3}{*}{$\begin{array}{l}\text { Amido Nativo } \\
\text { Condições de } \\
\text { Forneamento }\end{array}$} & \multicolumn{5}{|c|}{ Volume Específico $\left(\mathrm{cm}^{3} \mathbf{g}^{-1}\right)$} & \multirow[b]{3}{*}{ CV\% } \\
\hline & \multicolumn{2}{|c|}{ Método } & \multicolumn{3}{|c|}{ Material do molde } & \\
\hline & Tradicional* $^{*}$ & CV\% & Silicone & CV\% & $\begin{array}{c}\text { Politetra- } \\
\text { fluoretileno }\end{array}$ & \\
\hline 20 minutos a $200{ }^{\circ} \mathrm{C}$ & $1,92 \mathrm{~dB}$ & 11,45 & $3,14^{\mathrm{bA}}$ & 1,59 & $2,80^{\mathrm{cA}}$ & 6,78 \\
\hline 25 minutos a $200{ }^{\circ} \mathrm{C}$ & $3,01 \mathrm{cA}$ & 1,32 & $2,23 \mathrm{cc}$ & 0,89 & $2,62 \mathrm{cB}$ & 6,87 \\
\hline 20 minutos a $250^{\circ} \mathrm{C}$ & $3,58^{\mathrm{bA}}$ & 2,50 & 3,49 aA & 0,85 & $4,34^{\mathrm{aA}}$ & 7,60 \\
\hline 25 minutos a $250^{\circ} \mathrm{C}$ & $4,66{ }^{\text {aA }}$ & 3,00 & $2,13 \mathrm{dc}$ & 0,46 & $3,78 \mathrm{bB}$ & 6,61 \\
\hline
\end{tabular}

*Não apresentam diferença significativa letras iguais minúsculas na coluna para tempo e temperatura de forneamento e letras maiúsculas iguais na linha, para o tipo de material empregado ( $p>0,05)$ ou método tradicional com escaldamento (CEREDA, 1983). 

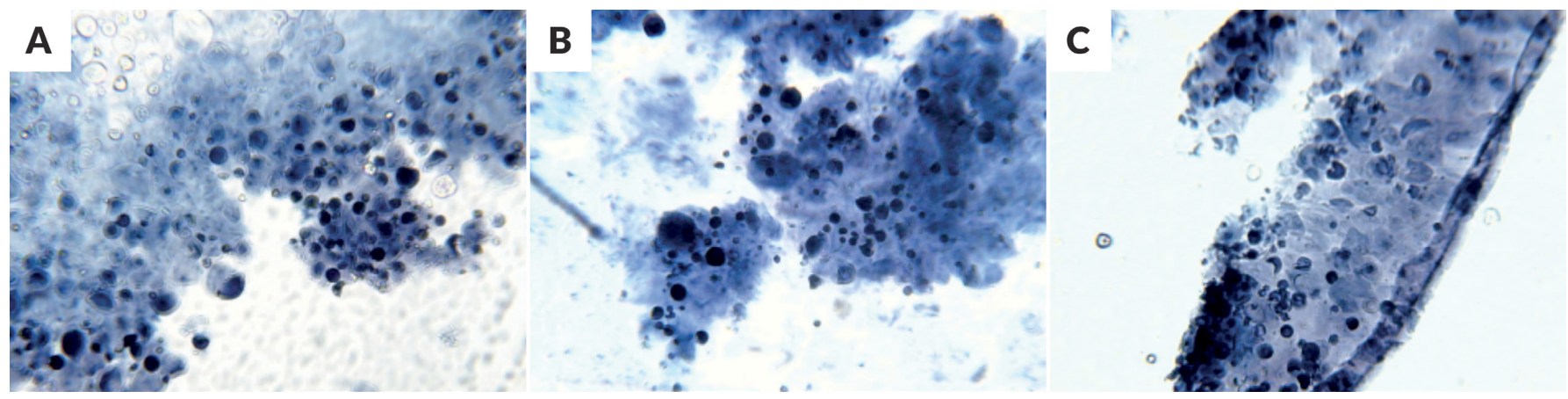

Figura 4. Microimagens de fragmentos das massas de polvilho azedo expandidas com forneamento a $200{ }^{\circ} \mathrm{C}$ durante 20 minutos. A) Molde de silicone; B) Molde de metal com politetrafluoretileno; C) Método tradicional com escaldamento (CEREDA, 1983).

Os resultados obtidos permitem observar que o método proposto é rápido e possibilita contornar as dificuldades apresentadas pelo método tradicional. Além de demorado e de difícil padronização, esse método (tradicional) apresentou grande variação entre as mensurações, razão pela qual exige grande quantidade de amostra e de repetições como forma de obter maior precisão.

Embora os maiores valores de expansão das amostras de amido analisadas tenham sido obtidos em temperatura de $250{ }^{\circ} \mathrm{C}$ (20 ou 25 minutos), a fragilidade das massas obtidas, que resultou na dificuldade de determinar as medidas, desqualificou a sua recomendação.

Quanto ao aspecto de gelatinização do amido para constituir a rede de carboidrato capaz de reter gás e manter a textura, as observações microscópicas (Figura 4) permitiram constatar a presença de amido em estado granular mesmo nas massas escaldadas, o que indica que a gelatinização não ocorre em sua capacidade total, mesmo no método tradicional.

Apesar de muito utilizado o método tradicional (CEREDA, 1983), houve dificuldade na comparação dos resultados obtidos de volume específico devido à variabilidade dos produtos empregados na elaboração das massas. Os resultados obtidos permitem avaliar várias condições de interação entre tempo, temperatura e procedimento adotado, estabelecendo assim a melhor condição para a recomendação do método rápido e simplificado.

\section{Conclusão}

A mistura direta de 5 gramas de amostra de amido com 5 mililitros de água destilada, em moldes de silicone e forneamento a $200^{\circ} \mathrm{C}$ durante 25 minutos, constituem as melhores condições para a obtenção de valores de volume específico de massas assadas de polvilho azedo e amidos com propriedade de expansão, enquanto que com o uso de metal revestido com politetrafluoretileno, a melhor condição é forneamento a $200{ }^{\circ} \mathrm{C}$ durante $\mathrm{O}$ tempo de 20 minutos.

\section{Agradecimentos}

À Coordenação de Aperfeiçoamento de Pessoal de Nível Superior (CAPES) e ao Conselho Nacional de Desenvolvimento Científico e Tecnológico (CNPq).

\section{Referências}

ANJOS, L. D.; PEREIRA, J.; COUTO, E. M.; CIRILLO, M. A. Modified starches or stabilizers in preparation of cheese bread. Ciência Rural, Santa Maria, v. 44, n. 9, p. 1686-1691, 2014. http://dx.doi.org/10.1590/0103-8478cr20131133.

APLEVICZ, K. S.; DEMIATE, I. M. Caracterização de amidos de mandioca nativos e modificados e utilização em produtos panificados. Ciência e Tecnologia de Alimentos, Campinas, v. 27 , n. 3, p. 478-484, 2007. http://dx.doi.org/10.1590/S010120612007000300009.

BERTOLINI, A. C.; MESTRES, C.; RAFFI, J.; BULÉON, A.; LERNER, D.; COLONNA, P. Photodegradation of cassava and corn starches. Journal Agricultural Food Chemistry, Easton, v. 49, n. 2, p. 675-682, 2001.

BRASIL. Agência Nacional de Vigilância Sanitária. Diretoria Colegiada. Resolução RDC n 263, de 22 de setembro de 2005. Regulamento técnico para produtos de cereais, amidos, farinhas e farelos. Diário Oficial [da] República Federativa do Brasil, Brasília, DF, 2005. Disponível em: <http://www4.anvisa. gov.br/base/visadoc/CP/CP\%5B8993-1-0\%5D.PDF>. Acesso em: 06 abr. 2015

BRASIL. Ministério da Saúde. Resolução n 12, de 24 de julho de 1978. A CNNPA do Ministério da Saúde aprova 47 padrões de identidade e qualidade relativos a alimentos e bebidas para serem seguidos em todo território brasileiro. Diário Oficial [da] República do Brasil, Brasília, DF, 1978.

CAMARGO, K. F.; LEONEL, M.; MISCHAN, M. M. Produção de biscoitos extrusados de polvilho azedo com fibras: efeito de parâmetros operacionais sobre as propriedades físicas. Ciência e Tecnolologia de Alimentos, Campinas, v. 28, n. 3, p. 586-591, 2008. 
CEREDA, M. P. Padronização para ensaios de qualidade de fécula fermentada de mandioca (polvilho azedo): I. Formulação e preparo de biscoitos. Boletim da Sociedade Brasileira de Ciência e Tecnologia de Alimentos, Campinas, v. 17, n. 3, p. 287-295, 1983.

DEMIATE, I. M.; KOTOVICZ, V. Cassava starch in the Brazilian food industry. Ciência e Tecnologia de Alimentos, Campinas, v. 31, n. 2, p. 388-397, 2011. http://dx.doi.org/10.1590/S010120612011000200017.

FRANCO, C. M. L.; OGAWA, C.; RABACHINI, T.; ROCHA, T. S.; CEREDA, M. P.; JANE, J. Effect of lactic acid and UV irradiation on the cassava and corn starches. Brazilian Archives of Biology and Technology, Curitiba, v. 53, n. 2, p. 443-454, 2010. http://dx.doi.org/10.1590/S1516-89132010000200025.

LEONEL, M.; GARCIA, A. C. B.; REIS, M. M. Caracterização físico-química e microscópica de amidos de batata-doce, biri, mandioca e taioba e propriedades de expansão após modificação fotoquímica. Brazilian Journal of Food Technology, Campinas, v. 7, n. 2, p. 129-137, 2004.

LOPEZ-TENORIO, J. A.; RODRIGUEZ-SANDOVAL, E.; SEPULVEDA-VALENCIA, J. U. Evaluación de características físicas y texturales de pandebono. Acta Agronomica, Palmira, v. 61, n. 3, p. 273-281, 2012.
MAEDA, K. C.; CEREDA, M. P. Avaliação de duas metodologias de expansão ao forno do polvilho azedo. Ciência e Tecnologia de Alimentos, Campinas, v. 21, n. 2, p. 139-143, 2001. http:// dx.doi.org/10.1590/S0101-20612001000200003.

MARCON, M. J. A.; KURTZ, D. J.; RAGUZZONI, J. C.; DELGADILLO, I.; MARASCHIN, M.; SOLDI, V.; REGINATTO, V.; AMANTE, E. R. Expansion properties of sour cassava starch (polvilho azedo): variables related to its practical application in bakery. Starch/Stärke, Weinheim, v. 61, n. 12, p. 716-726, 2009.

MILDE, L. B.; GONZALEZ, K. G.; VALLE-URBINA, C.; RYBAK, A. Pan de fécula de mandioca con leche. Comportamiento físico al adicionar un emulsionante. Revista de Ciencia e Tecnología, Misiones, v. 11, n. 11, p. 4-8, 2009.

PLATA-OVIEDO, M.; CAMARGO, C. Effect of acid treatments and drying processes on physico-chemical and functional properties of cassava starch. Journal of the Science of Food and Agriculture, London, v. 77, n. 1, p. 103-108, 1998. http:// dx.doi.org/10.1002/(SICI)1097-0010(199805)77:1<103::AIDJSFA10>3.0.CO;2-2.

WESTBY, A.; CEREDA, M. P. Production of fermented cassava starch (polvilho azedo) in Brazil. Tropical Science, London, v. 34, n. 2, p. 203-210, 1994. 